\title{
PREPARATION OF THIN FILMS FOR USE IN GENERATING NEUTRAL PARTICLE BEAMS*
}

\section{Introduction}

The Isotope Research Materials Laboratory (IRML) at the Oak Ridge National Laboratory (ORNL) was requested to prepare large-area, thin aluminum foils for use in beam neutralization experiments. The specific requirements were that the foils be $7.15 \mathrm{~cm}$ in diameter and have thicknesses in the range of 5 to $20 \mu \mathrm{g} / \mathrm{cm}^{2}$ (185 to $740 \AA$ ). The foils were exposed to a $\mathrm{H}^{-}$beam of $50 \mathrm{MeV}$ to determine foil lifetimes for peak beam-current densities of $15.3 \mathrm{~mA} / \mathrm{cm}^{2}$ in a $50-\mu \mathrm{s}$ pulse at 1 to $3 \mathrm{~Hz}$. The major experimental objective was to determine the optimum foil thickness for converting $\mathrm{H}^{-}$to $\mathrm{H}^{\circ}$.

The IRML is a part of the Isotopes Section in the Operations Division at ORNL. The isotope program at ORNL was established to provide both stable and radioactive isotopic research materials, to fabricate samples, and to provide associated services to fill both domestic and foreign requests. One basic quideline, which is adhered to by the ORNL isotope program, is that this program will not: compete with domestic companies and will provide the material and/or services only if they cannot be obtained conmercially or if they are for other Jepertment of Energy prosrams.

Although the ORNL isotope program was established in 1946, the IRML, which specializes in fabricating both stable and radioactive isotopic materials in specific cumpound forms or geometrical shapes, was established in 1960. Since that time, IRML has prepared samples of most of the isotopes of the elements in the periodic chart. The specific eiements processed are shown in Fig. 1. The broad experience in material processing in general and thin-film fabrication in particular resulted in IRML being requested to fabricate the largearea, thin-film aluminum foils for use in hydrogen-beam neutralization experiments.

Typical physical vapor deposition processes used by IRML in preparing thin films have included sputtering, electron-bombardment evaporation, vaporization by radicfrequency ( $r f$ ) induction heating, and evaporation by resistance heating.

Sputter deposition involves the bombardment of the target material with energetic inert-gas ions (typically argon). The target material (usually 8to $13-\mathrm{cm}$ diam) forms the cathode of the system. As the ions strike the cathode, target atoms or clusters of atoms are ejected by momentum transfer from the incident ions. The collecting substrate is attached to the anode and is subsequently coated by the ejected target atoms. This technique can be used for depositing both conducting and insulating materials. (1) The major disadvantages of this technique are that in typical sputtering systems a large quantity of material is needed to prepare the sputtering target and the resulting deposition is 1 imited in size to $12.7-\mathrm{cm}$ diameter with the majority of sputtering systems. The large quantity of material required for sputtering

*Research sponsored by the Division of Basic Energy Sciences and Division of Nuclear Sciences, U.S. Department of Energy, under contract DE-AC05-840R21400 with the Martin Marietta Energy Systems, Inc. 


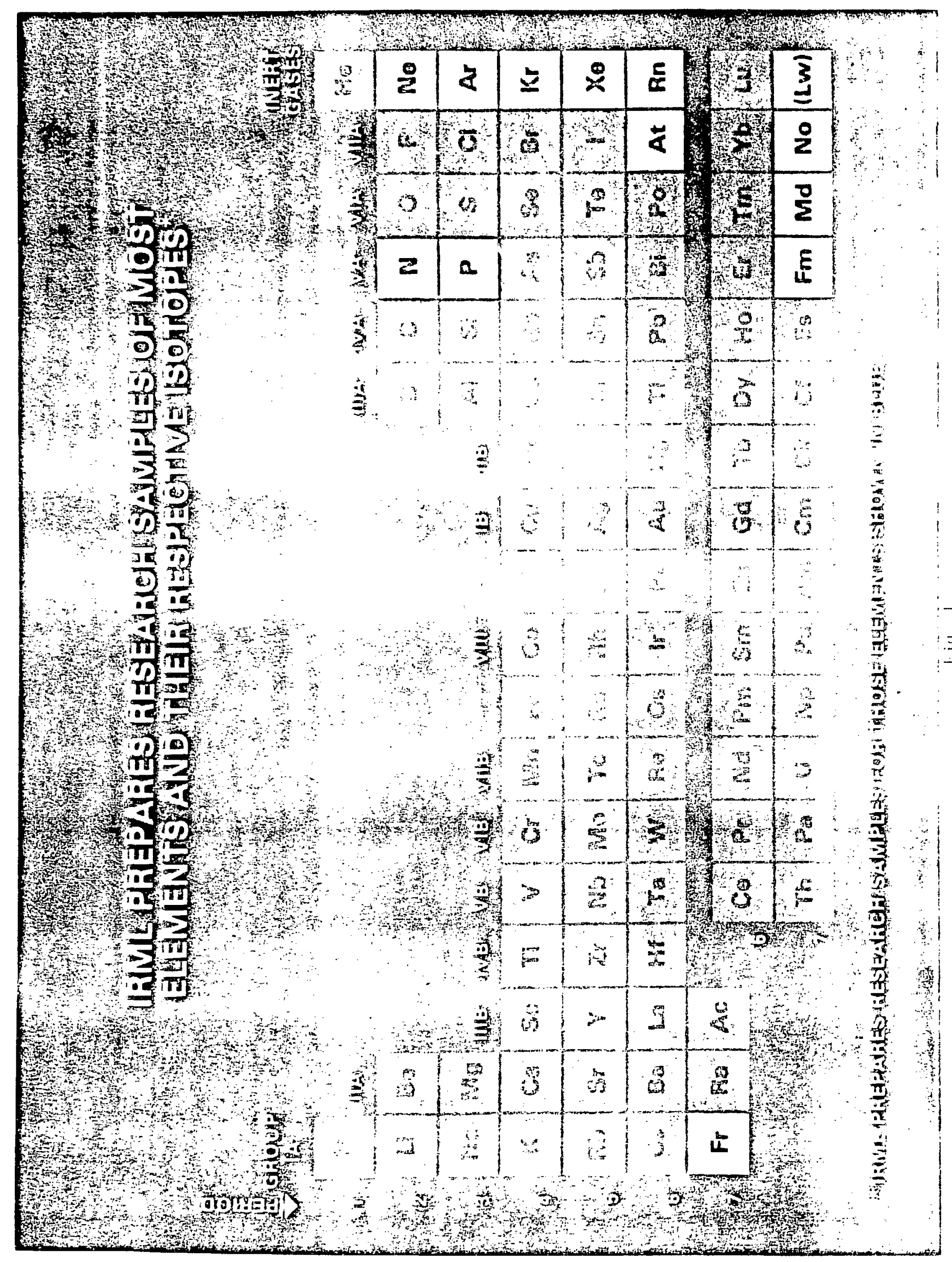


targets is typically no problem unless the desired material is an enriched isotope. For many highly enriched isotopic materials, there is usually insufficient material to fabricate the sputtering target. This problem has essentially been eliminated by using a focused ion-beam sputtering technique, schematically shown in Fig. 2. A duoplasmatron ion source is used to generate inert-gas ions in a chamber that is maintained at approximately $1.5 \mathrm{~Pa}$. The ions are accelerated into an electrostatic and magnetic lens system leading into a vacuum chamber that is maintained at approximately $10^{-4} \mathrm{~Pa}$. The inertgas ion beam can be focused to a spot size of approximately $2 \mathrm{~mm}^{2}$, thus allowing very small quantities of material to be used as the sputtering target.

For low-vapor-pressure, high-melting-point materials (metals or ceramics), electron--bombardment (eb) heating is normally used to vaporize the material. In the eb jrocess, electrons from an ohmically heated thoriated-tungsten filament are accelerated toward a crucible containing the evaporant or are caused to impinge directly on a pellet of the material to be vaporized as shown in $\mathrm{Fig}$. 3. A schematic representation depicting a typical setup used in preparing both thin and thick material deposits is shown in Fig. 4.

Vaporization by rf induction heating is accomplished by heating the evaporant directly (metals) or heating a crucible containing the evaporant (metals and ceramics). The alternating magnetic field inside the induction coil induces a current in a conductive material placed within the coil and, thus, heats the conductor resistively. This technique has advantages over direct resistance heating in that the induction coil can be placed outside the vacuum environment, temperature gradients can be established along the length of a crucible so that lower-vapor-pressure impurity components can be condensed, and high temperatures can be achieved (>2300K) with simple coil designs. As with direct resistance heating, possible contamination from the crucible and possible incompatibility of the evaporant with the crucible are the major disadvantages. A schematic of a typical equipment assembly used to vaporize materials by rf heating is shown in Fig. 5 .

For those materials that have high vapor pressures at moderate temperatures ( $\leq 1800 \mathrm{~K})$, resistance or ohmic heating is frequently employed to cause vaporization. This technique involves passing a high current at relatively low voltage through a suitable filament or crucible. The heat produced is equal to $I 2 R$, where $I$ is the current and $R$ is the resistance of the filament or crucible. A major advantage of this technique is the minimal equipment investment required.

The eb and resistance vaporization processes were selected for preparing the large-area, thin aluminum foils. Resistance heating proved to be the best technique. Details of the fabrication and characterization of the aluminum foils are described below.

\section{Fabrication of Thin, Large-Area Aluminum Foils}

Initially, several aluminum evaporations were made using either eb or resistance heating. The material was vaporized and then condensed on glass substrates that were coated with a water-soluble parting agent. The eb 
SCHEMATIC OF FOCUSED ION BEAM SPUTTERING SYSTEM

USED FOR EFFICIENT DEPOSITION OF SMALL QUANTITIES OF ISOTOPIC MATERIALS

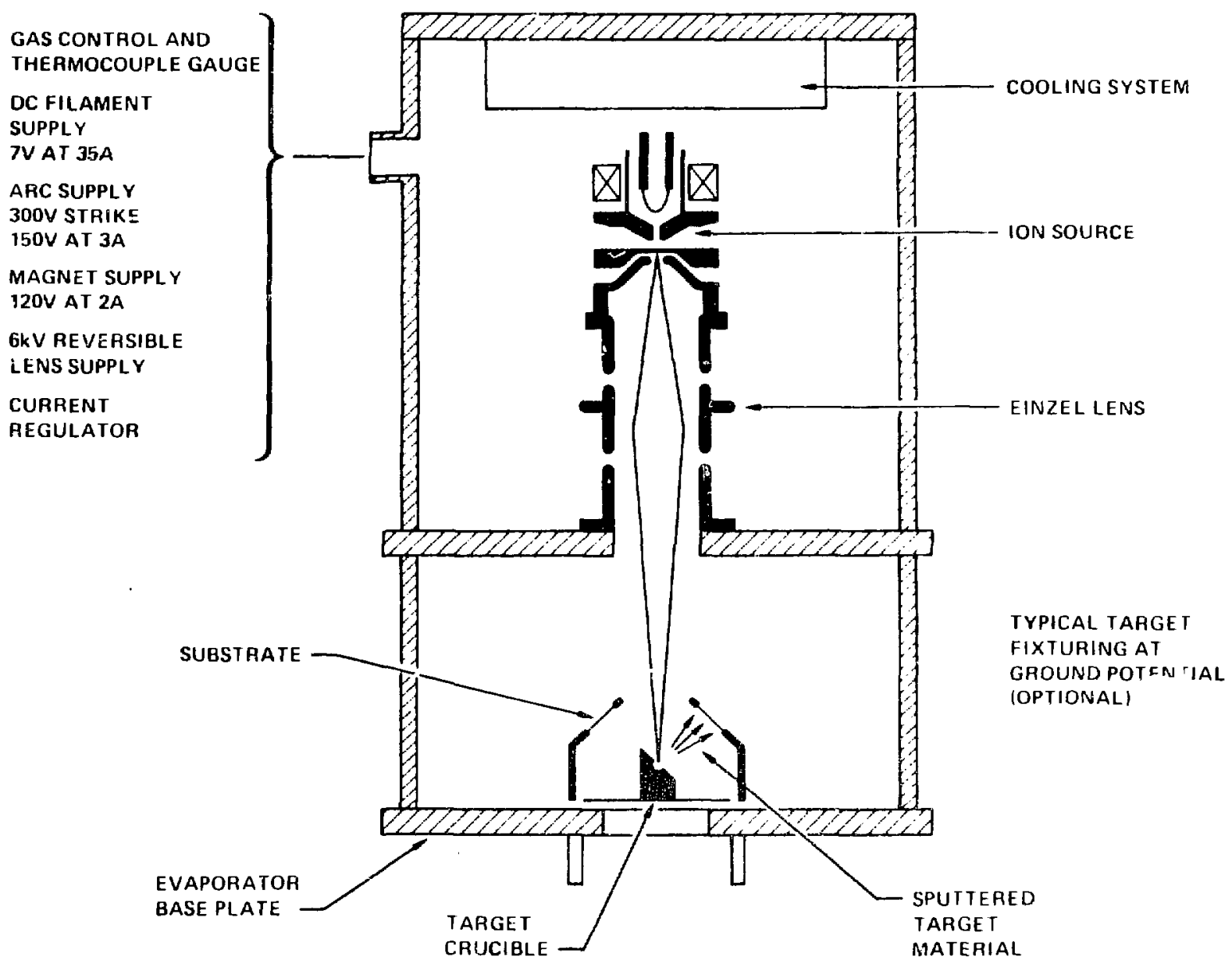

Fig. 2 


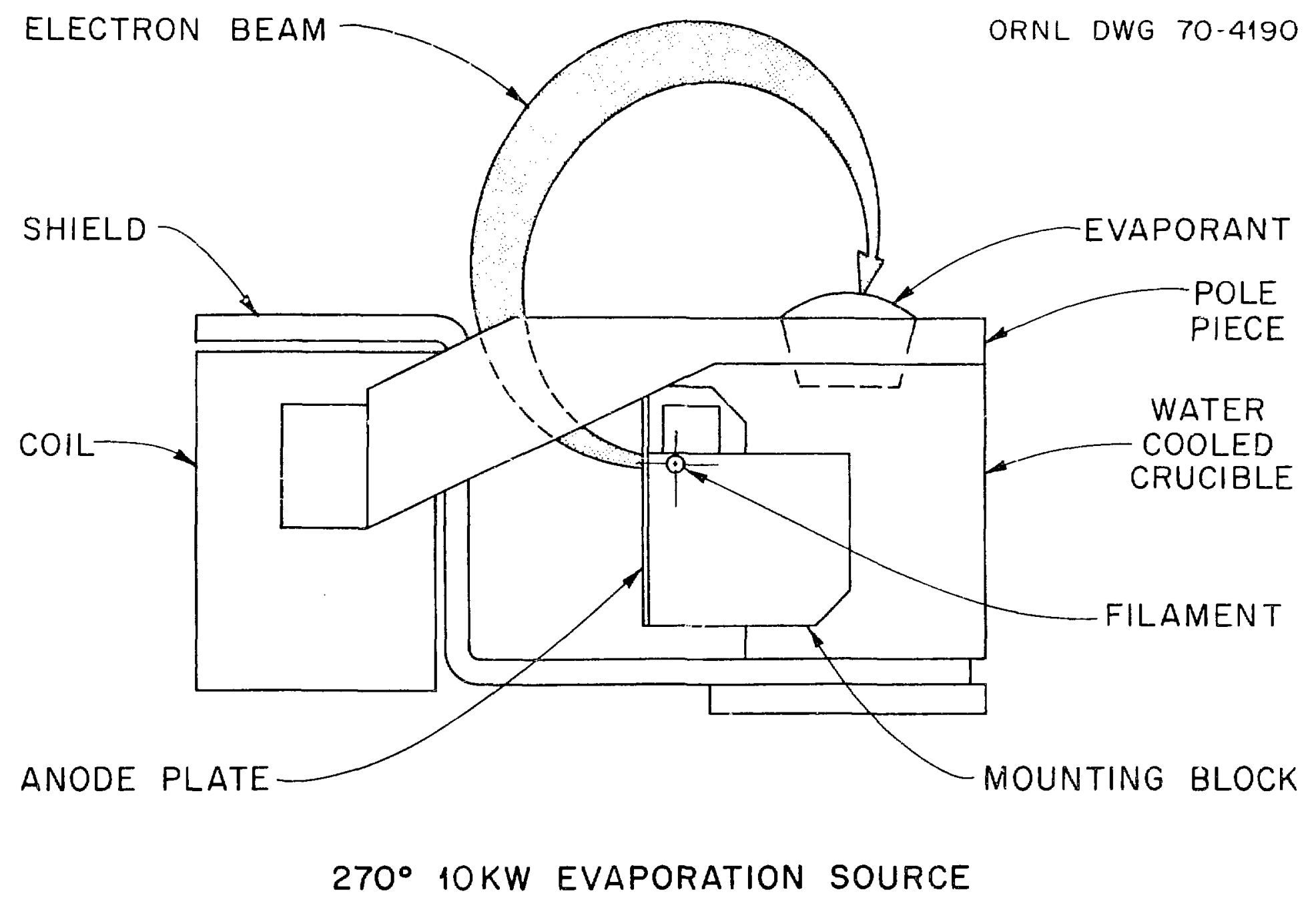

Fig. 3 
ORNL-DWG 77-18074

$61 \mathrm{~cm} \mathrm{DIAM} \times 76 \mathrm{~cm} \mathrm{HIGH}$

SS BELL JAR

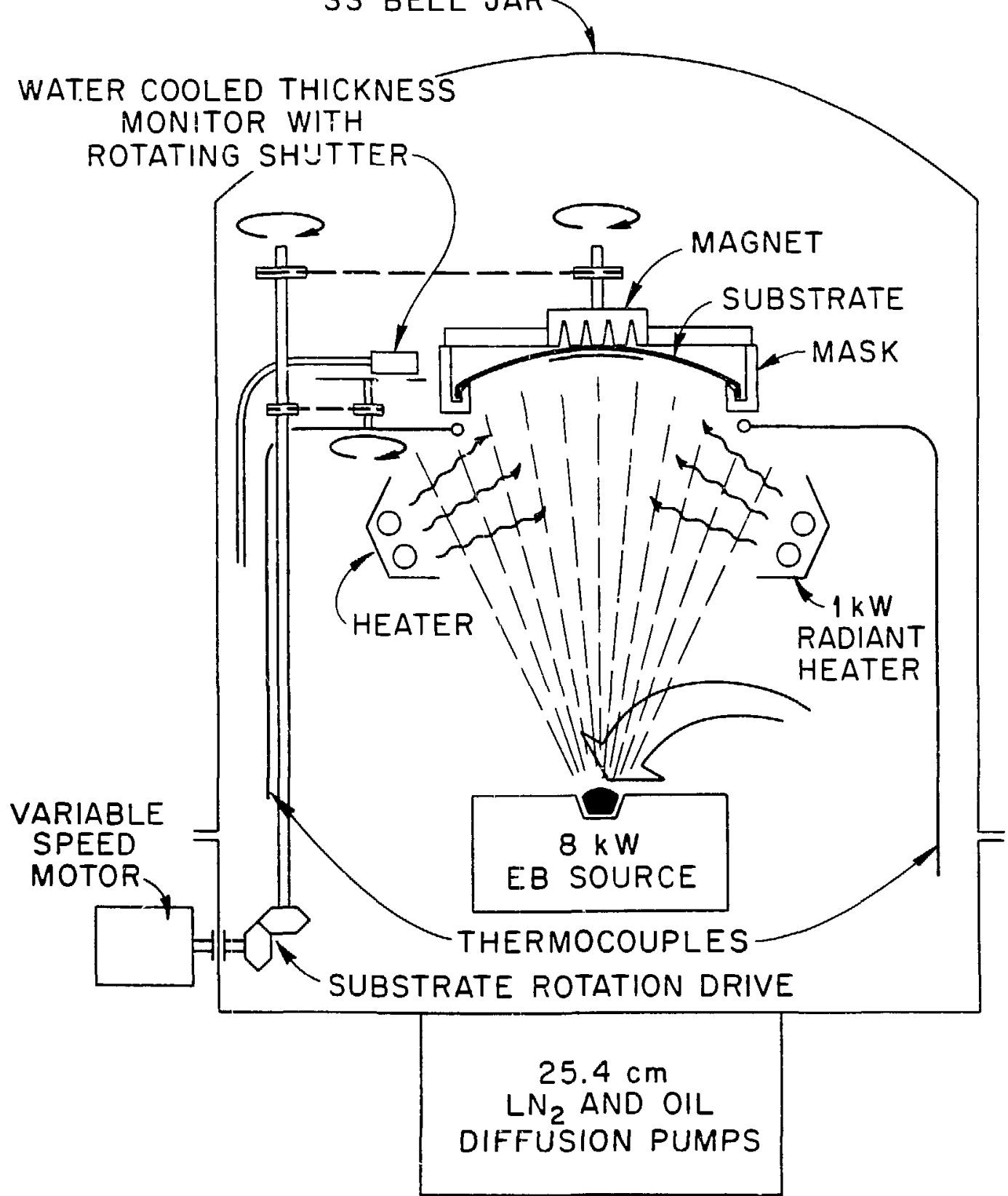

Fig. 4. Schematic of Typical Setup Used in Preparing Samples by Electron-Beam Evaporation 
ORNL-DWG T3-15807

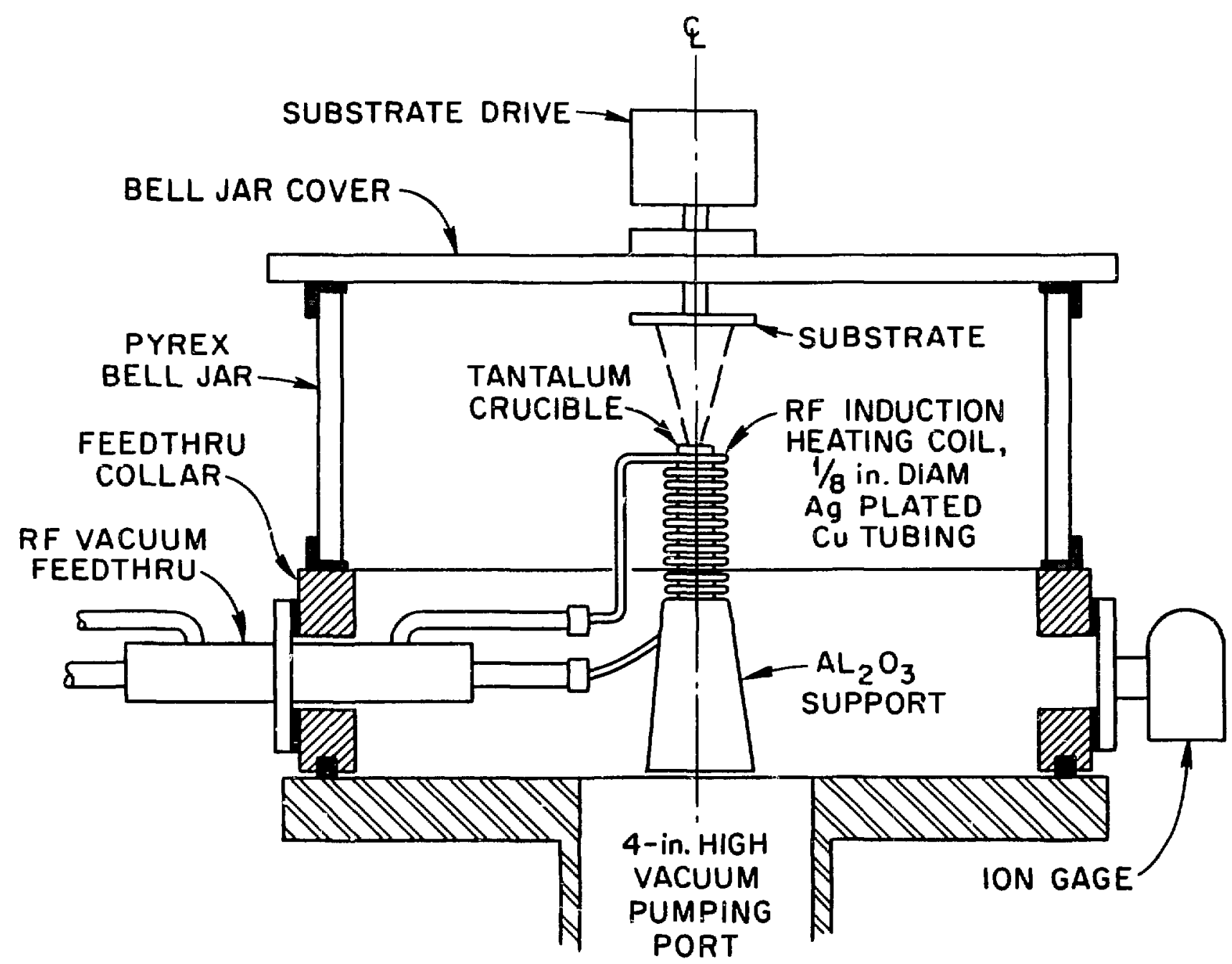

Fig. 5. Schematic of Typical Setup Used in Preparing Samples by Radiofrequency Induction Heating 
process involved using a source similar to the schematic shown in Fig. 3 and accelerating the electrons from the filament to impinge directly on the aluminum. The evaporation time required varied between 3 to 5 min depending on the film thickness desired. The resistance-heating process involved placing the aluminum to be evaporated directly on a tungsten filament and heating the filament to the desired temperature. The normal aluminum evaporation time was 10 to $15 \mathrm{~s}$. Both eb-and resistance-heating processes were conducted in a high-vacuum environment.

The aluminum foils prepared by resistance heating exhibited better properties during preparation and handiing. It was found that larger-area and stronger foils could be prepared by this technique. The foils prepared by the eb process were difficult to separate from the substrate and frequently broke into much smaller foils.

The vacuum system used in preparing the 7.6-cm-diam aluminum foils for the Argonne National Laboratory (ANL) hydrogen-beam neutralization experiments is shown in Fig. 6. The system is pumped with a 10-in. oil diffusion pump that has a pumping speed of $5300 \mathrm{~L} / \mathrm{s}$ for air. A water-cooled baffle is used to reduce the oil backstreaming into the vacuum chamber. Front views of the system and power supply are shown in Fig. 7. An interior view of the 32-in. $x$ 32-in. $x$ 32-in. vacuum chamber that shows the filament and substrate is shown in Fig. 8.

The aluminum foil fabrication involved placing an appropriate amount of aluminum for a desired thickness on the tungsten filament. The aluminum was in the form of a thin strip that was wrapped around the 9.5-in.-diam tungsten filament at eight equally spaced locations. The starting aluminum material used in the evaporations had a chemical purity of $99.999 \%$. The $9.5-\mathrm{cm} \times 7.0-\mathrm{cm}$ glass substrate was cleaned with a Knox-60 glass-cleaning solution and then dried. The parting agent (Betaine-sucrose) is applied to the substrate by spacing several drops over the surface and then spreading the material uniformly on the slide until the sucrose crystalizes. No polishing of the parting agent is done. After the filament has been loaded with aluminum and the substrate (coated with the Betaine-sucrose parting agent) has been installed $40 \mathrm{~cm}$ above the filament, the system is pumped dowr to approximately $10^{-4} \mathrm{~Pa}$; the filament is heated until the aluminum strips melt and wet the filament. The filament current is quickly increased to flash evaporate the aluminum in 10 to $15 \mathrm{~s}$. After the system is cooled down, the substrate is removed, and the foils are floated in water and picked up on nickel-grid frames. The nickel grid wire is approximately $0.003 \mathrm{~mm}$ thick and $0.05 \mathrm{~mm}$ wide. The twelve-wire-per-centimeter nickel grids used have a transmission of 90\%. A frame with the nickel grids is shown in Fig. 9. A 7.6-cm-diam al uminum foil approximately $10 \mu \mathrm{g} / \mathrm{cm}^{2}$ is shown in $\mathrm{Fig} .10$. The procedure described above has also been used to prepare $15-$ to $20-\mu \mathrm{g} / \mathrm{cm}^{2}$ aluminum foils $20 \mathrm{~cm} \times 20 \mathrm{~cm}$.

\section{Foil Thickness and Uniformity}

Accurate determinations of the thickness of foils in this range is a difficult task. The aluminum foil thickness and uniformity were measured by weight, light transmittance, or the change in energy of alpha particles. During the actual evaporation, weighing discs were symmetrically located around the edge of the glass substrate, and the weight gained during the evaporation was 


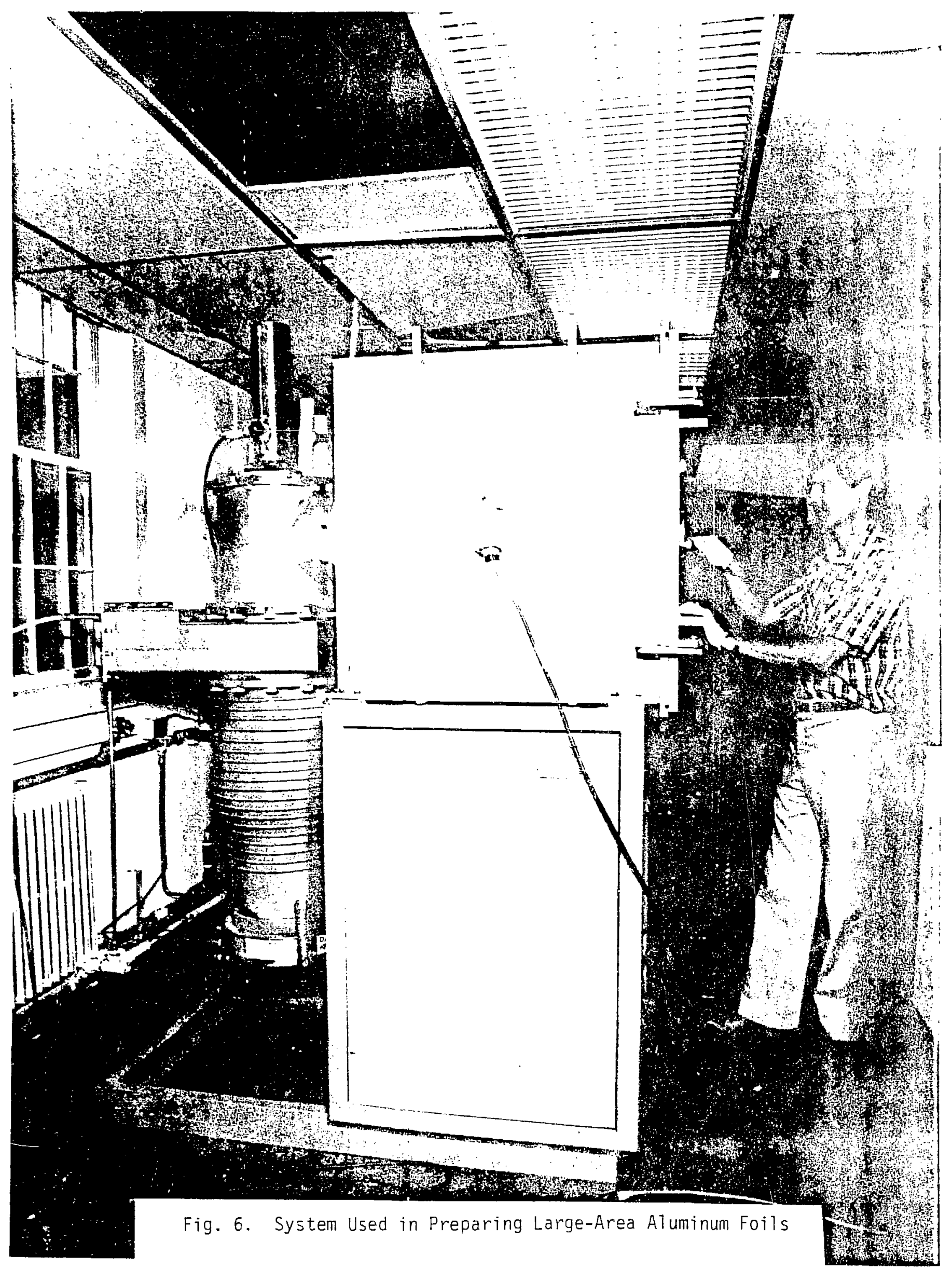




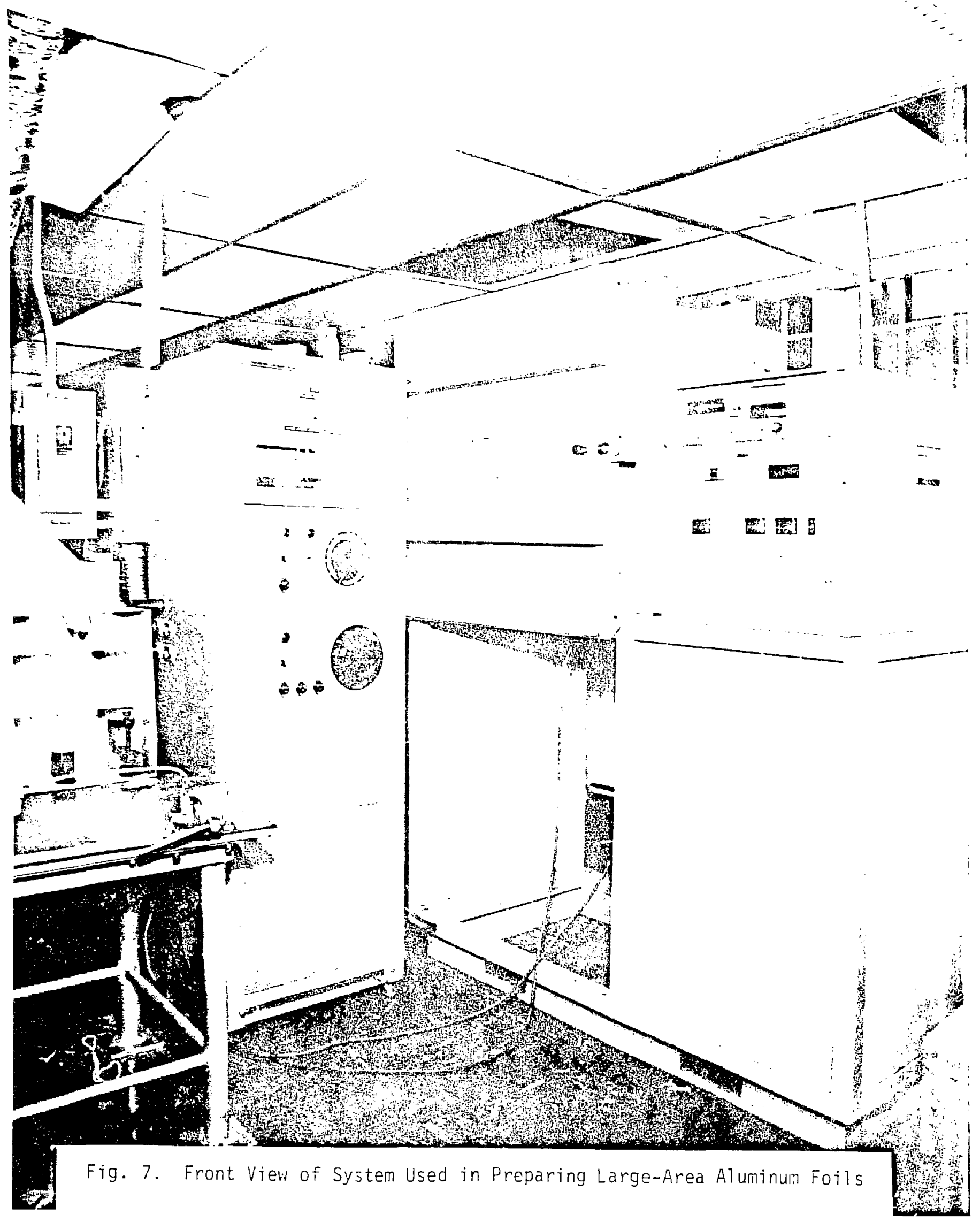



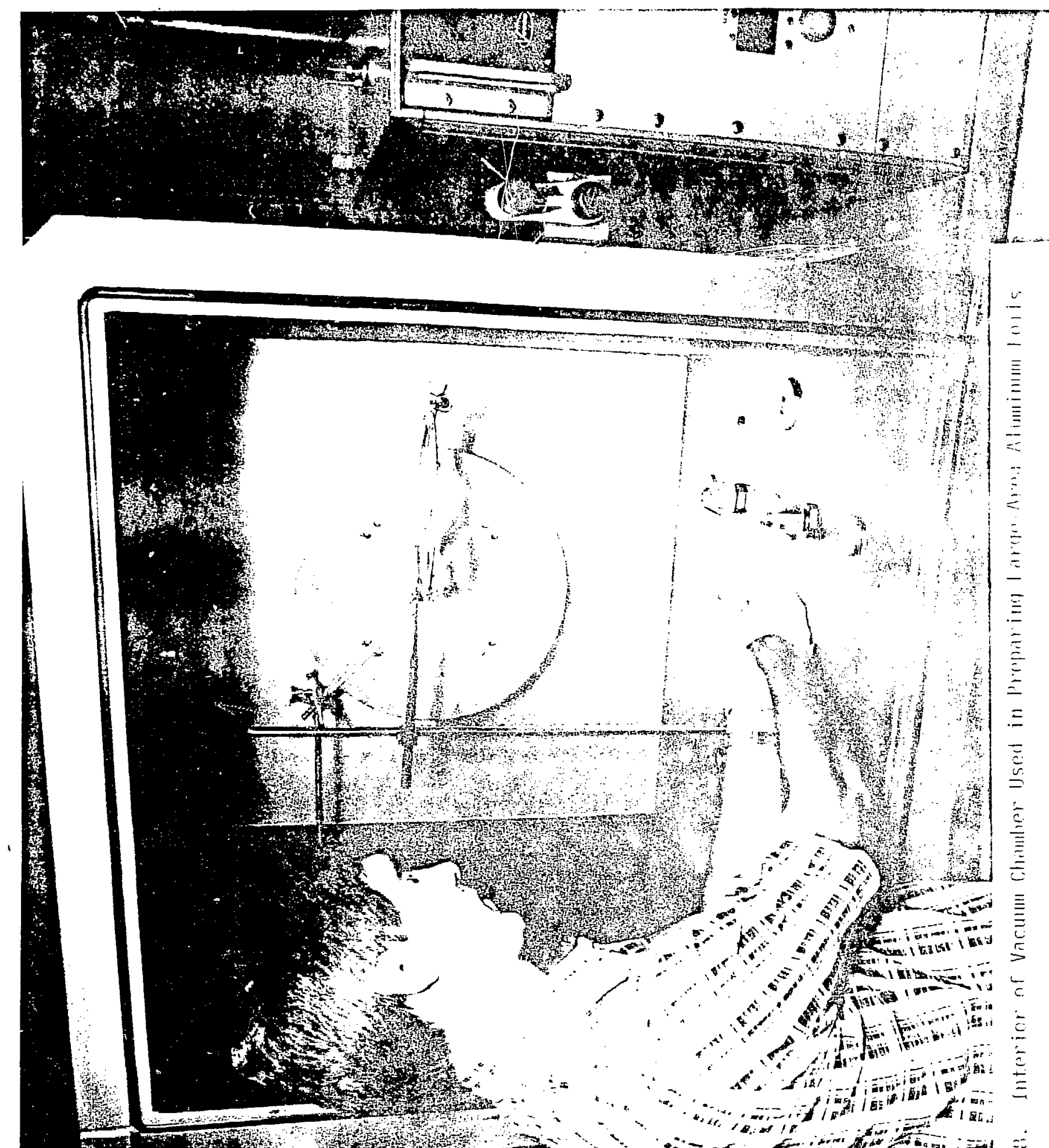

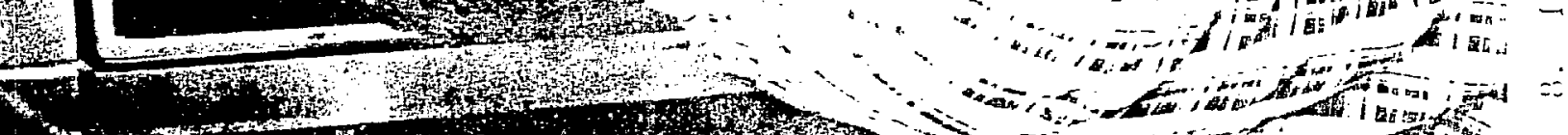
然

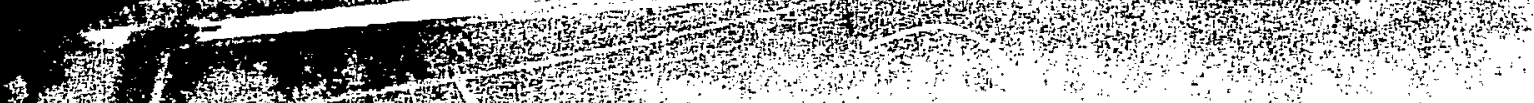




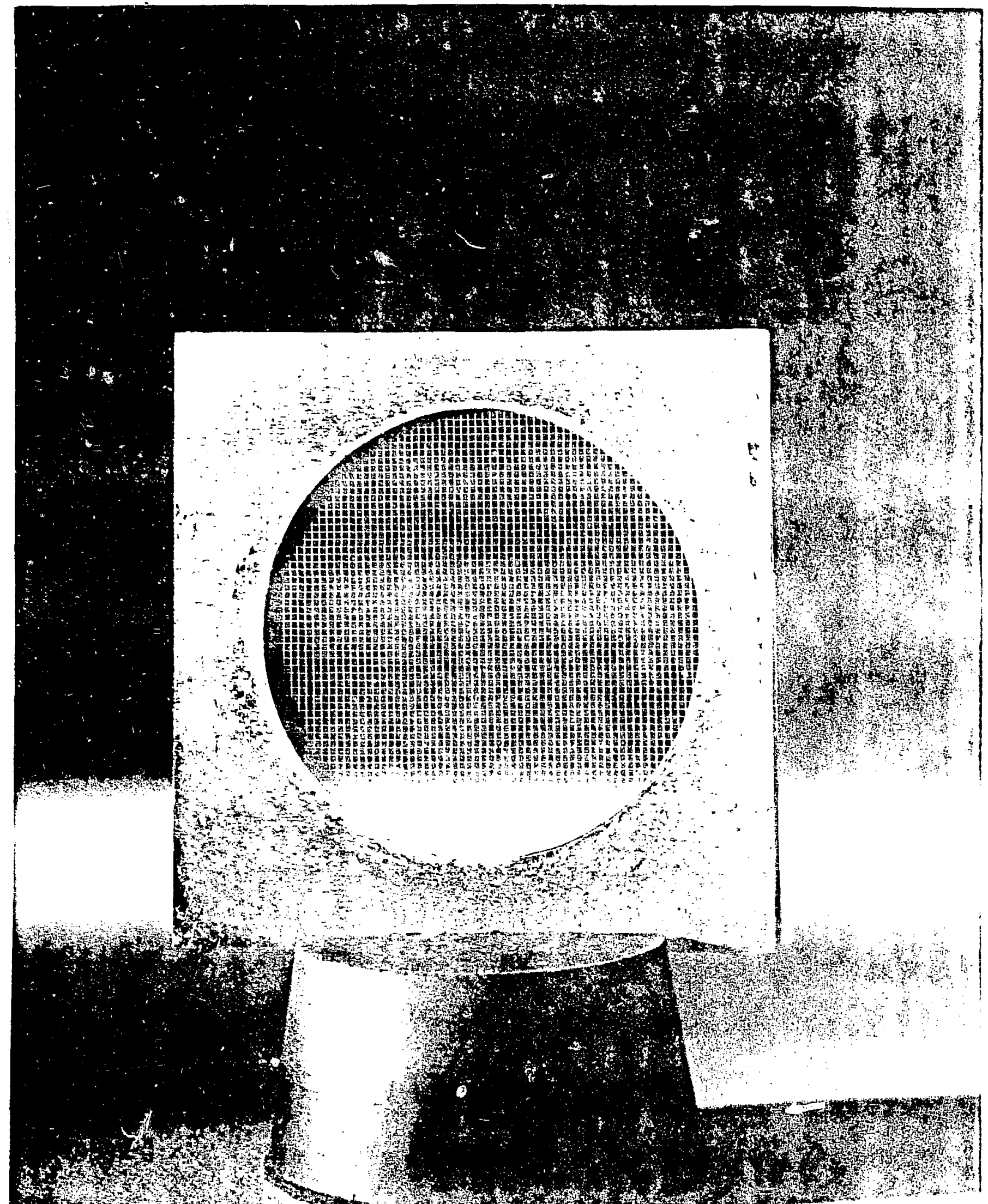

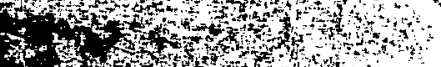

Fig. 9. Three-inch Internal Diameter Gridded Substrate Holder Used for Hounting Aluminum Foils Used in ANL Beam Neutralizer Experiment 


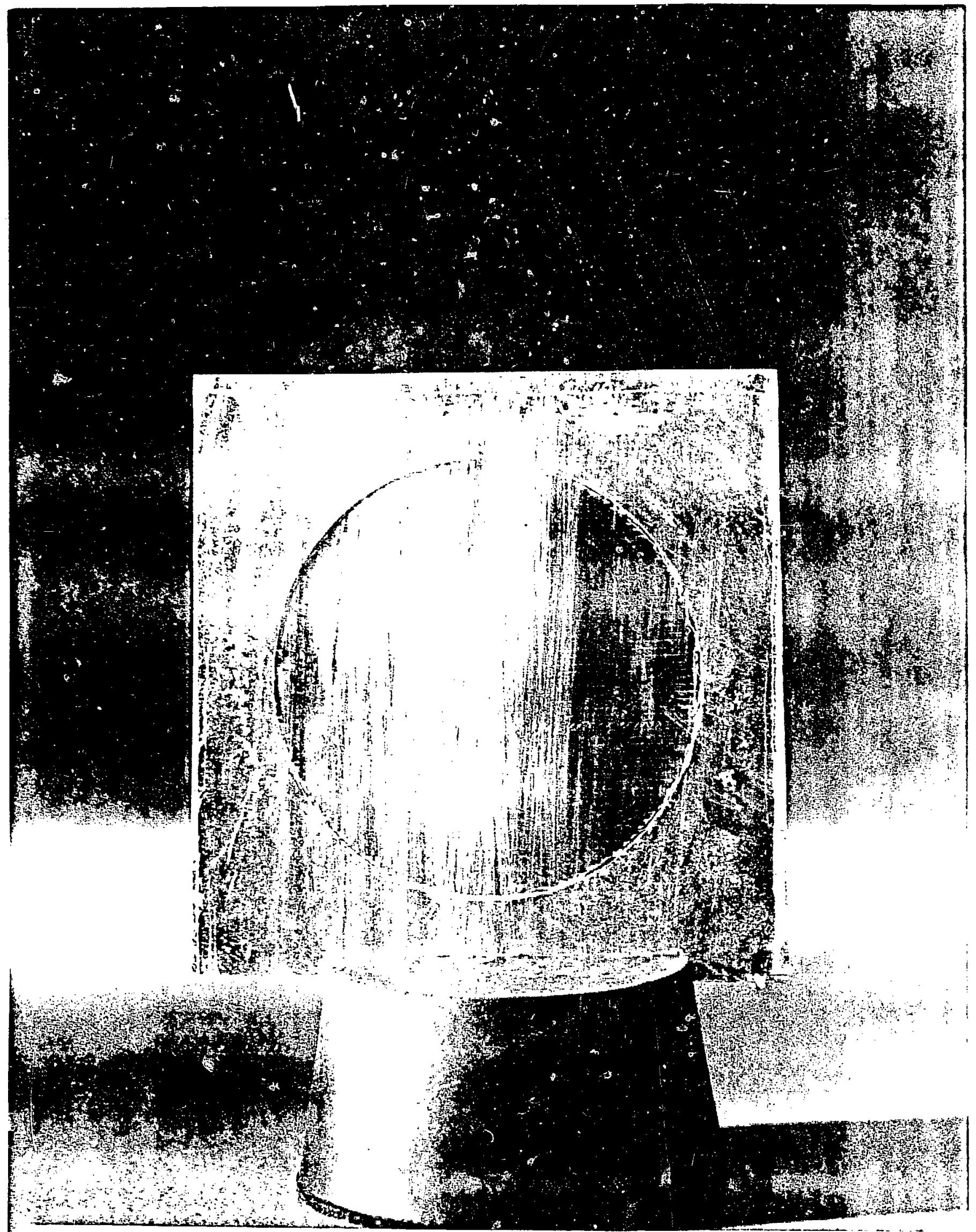

Fig. 10. Ten-microgram/cm2 Aluminum Foil Mounted on Gridded Substrate Holder 
determined. Separate evaporations using the same quantity of starting material and the same geometrical arrangement used for the actual aluminum foil evaporation were used to determine foil uniformity by determining the weight gain of nine weighing discs symmetrically located along the diameter of the substrates.

After the aluminum foils were removed from the substrate, light transmittance was used for a very rough check of the uniformity of foil thickness.

During the actuil hydrogen-beam neutralization runs at ANL, there were indications that the foils were thicker than the weight data indicated. Since the we ight data represented a small weight gain (40 to $50 \mu \mathrm{g}$ ) on a weighing disc that weighed over $100 \mathrm{mg}$, a more accurate foil thickness measurement technique was sought. An alternate technique was to measure the change in energy of alpha particles through the various foils. Determining this vaiue and using the known stopping-power data for aluminum for specific-energy alpha particles, the foil thickness and uniformity could be determined. The major uncertainty in this measurement would be the stopping-power data which are believed to be accurate to $\pm 10 \%$.

An Am-241 source, which has a peak alpha energy of approximately $5.5 \mathrm{MeV}$, was used for the foil thickness and uniformity determinations. The Am-241 source was collimated to 2-mm diameter and allowed to impinge on 1-cm-diam portions of the aluminum foil. For these measurements, self-supported foils were used to eliminate any grid effects. The $1-\mathrm{cm}$ portions were taken from equally spaced locations along the diameter of the 7.6-cm-diam foil. Results of thes: measureirients for two foils lised in the ANL experiments are shown in Table 1. Only two foils were measured for foil Number 63 since two foils were broken: Weight data indicated that foil Number 68 had a thickness of 12 to $13 \mu \mathrm{g} / \mathrm{cm}^{2}$ and foil Number 63 had a thickness of 5 to $6 \mu \mathrm{g} / \mathrm{cm}^{2}$. For heavier aluminum foils, the weight data and alpha thickness data appear to be in reasonably guod agreement. For example, an aluminum foil of $89 \mu \mathrm{g} / \mathrm{cm}^{2}$ by weight was determined to be $91 \mathrm{\mu g} / \mathrm{cm}^{2}$ by the alpha energy loss method. The alpha energy loss method will continue to be used for the aluminum foil thickness and uniformity measurements.

Table 1. Thickness and uniformity determination of aluminum deposits used in ANL tests by alpha energy loss method

Sample number $\Delta E(\mathrm{KeV}) \quad$ Fi im thickness $\left(\mu \mathrm{g} / \mathrm{cm}^{2}\right)$

- Fo1 Number 68

$\begin{array}{lll}1 & 11.0 & 19.3 \\ 2 & 11.0 & 19.3 \\ 3 & 11.0 & 19.3 \\ 4 & 10.0 & 17.6\end{array}$

- Foil Number 63 


\section{Conclusions}

A technique has been developed for preparing large-area, thin alumilium foils which perform very well when bombarded by energetic $\mathrm{H}^{-}$ions. Future development efforts will be directed at increasing the foil size and improving the grid material. Lower atomic number grid materials are being investigated to minimize interaction of the beam with the grid without jeopardizing the mechanical integrity of the foil/grid system.

\section{Reference}

(1)R. J. Hill, Physical Vapor Deposition, Airco Temescal (1976), p. 103. 


\section{DISCLAIMER}

This report was prepared as an account of work sponsored by an agency of the United States Government. Neither the United States Government nor any agency thereof, nor any of their employees, makes any warranty, express or implied, or assumes any legal liability or responsibility for the accuracy, completeness, or usefulness of any information, apparatus, product, or process disclosed, or represents that its use would not infringe privately owned rights. Reference herein to any specific commercial product, process, or service by trade name, trademark, manufactuier, or otherwise does not necessarily constitute or imply its endorsement, recommenciation, or favoring by the United States Government or any agency thereof. The views and opinions of authors expressed herein do not necessarily state or reflect those of the United States Government or any agency thereof. 